\title{
Photodegradation of Sulfamethoxypyridazine in UV/Co(II)/ Peroxymonosulfate System: Kinetics, Influencing Factors, Degradation Pathways, and Toxicity Assessment
}

\author{
Xiaolan Zeng • Xiaozi Sun • Yu Meng • \\ Ningning Yu $\cdot$ Jing Liu
}

Received: 23 February 2021 / Accepted: 12 September 2021 / Published online: 1 October 2021

(C) The Author(s), under exclusive licence to Springer Nature Switzerland AG 2021

\begin{abstract}
Sulfonamides (SAs) including sulfamethoxypyridazine (SMP) are regarded as a new type of persistent pollutant at present due to their abuse. In this work, the direct photodegradation behavior of 11 SAs under simulated sunlight was first investigated, and the results indicated that the direct photolysis of SMP is the slowest among these SAs. Then the oxidation degradation of SMP in UV/Co(II)/ peroxymonosulfate (PMS) system was systematically explored. Up to $95.2 \%$ removal of $0.071 \mathrm{mM}$ SMP was observed after $20 \mathrm{~min}$ of reaction under the optimal condition with a molar ratio of 1:150:5 between SMP, PMS, and Co(II). The effects of some coexisting anions on degradation of SMP were investigated. It was found that $\mathrm{Cl}^{-}$and high concentrations of $\mathrm{CO}_{3}{ }^{2-}$ and $\mathrm{HCO}_{3}{ }^{-}$have a significant inhibitory effect, while $\mathrm{HPO}_{4}{ }^{2-}$ has only a slight positive
\end{abstract}

Supplementary Information The online version contains supplementary material available at https://doi. org/10.1007/s11270-021-05351-5.

X. Zeng $\cdot$ X. Sun $\cdot$ Y. Meng $\cdot$ N. Yu $\cdot$ J. Liu

College of Chemistry and Chemical Engineering,

Xinyang Normal University, Henan Xinyang 464000,

People's Republic of China

X. Zeng ( $ه)$

Henan Key Laboratory for Synergistic Prevention of Water and Soil Environmental Pollution, Xinyang

Normal University, Henan Xinyang 464000,

People's Republic of China

e-mail: zx16688@163.com effect. Radical scavenger experiments indicated that hydroxyl radicals $\left(\mathrm{HO}^{\bullet}\right)$ are prevailing active species responsible for SMP removal in UV/Co(II)/PMS system. The degradation of SMP in UV/Co(II)/PMS system was accomplished mainly by hydroxylation of the aromatic ring, extrusion of $\mathrm{SO}_{2}$, oxidation of $\mathrm{NH}_{2}$ group, and $\mathrm{N}-\mathrm{S}$ bond cleavage. Eight intermediates for SMP degradation were identified, and their toxicities to aquatic organisms were predicted by using the ECOSAR program based on the structure-activity relationships (SARs), which suggested that the chronic toxicities of SMP and its degradation intermediates are more significant than their acute toxicities. The present research indicates that UV/Co(II)/ PMS system is applicable for SMP degradation in aqueous solutions and may be helpful to understand the transformation behavior of SAs.

Keywords Sulfamethoxypyridazine $\cdot$ Degradation kinetics $\cdot \mathrm{UV} / \mathrm{Co}(\mathrm{II}) /$ peroxymonosulfate $\cdot$ Influencing factors $\cdot$ Degradation pathways $\cdot$ Toxicities

\section{Introduction}

Sulfonamide (SA) antibiotics have been used extensively in human medicine, livestock production, and aquaculture for disease treatment and prevention (Kong et al., 2015; Milić et al., 2013; Song et al., 2017). However, most sulfonamides (SAs) cannot be completely absorbed by humans and animals, 
thus, large amounts of residual antibiotics have been introduced into the aquatic environment (Lapworth et al., 2012). In particular, more than 10 types of SAs have been detected with high concentrations in various environment mediums including water, sediment, and soil (Dong et al., 2016; Song et al., 2018; Verlicchi et al., 2012). Moreover, the adverse effects of SAs such as toxicity to organisms, drug resistance increase, and the production of resistant genes have been reported to pose a threat to the ecological environment and human health (Batista et al., 2016; Yin et al., 2018). In addition, SAs can persist in the environment for a long time because of its poor biodegradability and low removal efficiency by the conventional treatments (Batista et al., 2016; Yin et al., 2018). Therefore, it is necessary to develop effective methods for the removal of SAs in aquatic environments.

Up to now, various methods including biological, physical, and chemical treatments have been developed for the elimination of those SAs in water. In general, the removal efficiency of biological and physical technologies are low and they can only be applied to the pretreatment of drinking water and wastewater. Whereas, the most commonly studied chemical methods for water treatment are the advanced oxidation processes (AOPs) (Al-Maqdi et al., 2018; Wang et al., 2019). Hydroxyl radical (HO ${ }^{\bullet}$ ) and sulfate radical $\left(\mathrm{SO}_{4}{ }^{-\bullet}\right)$-based AOPs have been developed into an efficient technology for the removal of organic pollutants in aqueous environments. $\mathrm{HO}^{\bullet}$ and $\mathrm{SO}_{4}{ }^{-\bullet}$ are typically generated by the activation of oxidants such as peroxymonosulfate (PMS) and persulfate (PS), and the activation methods include ultrasonic (Hori et al., 2012), heat (Pan et al., 2018; Sakulthaew et al., 2020), transition metals (TM) (Feng et al., 2017; Pan et al., 2017; Yao et al., 2019; Zeng et al., 2017), and UV (Qi et al., 2019). Previous studies have shown that some combination systems of UV and TM such as UV/TM/ PMS and UV/TM/PS systems can improve the degradation rate of target pollutants by co-activating PS or PMS (Nie et al., 2018).

So far, many studies have shown that $\mathrm{HO}^{\bullet}, \mathrm{SO}_{4}{ }^{-\bullet}$, or other reactive species-based AOPs have been successfully applied to remove some SAs in various aqueous environments. However, most previous studies focused on the removal of several SAs such as sulfadiazine (SDZ) (Liu et al., 2018; Zhang et al., 2020), sulfamethazine (SMZ) (Payan et al., 2019; Wu et al., 2019), sulfadimethoxine (SDM) (Yang et al., 2018) and sulfamethoxazole (SMX) (Du et al., 2020; Qiu et al., 2019; Wang \& Wang, 2018). As far as we know, few studies on the degradation of sulfamethoxypyridazine (SMP) using $\mathrm{HO}^{\bullet}$ and $\mathrm{SO}_{4}{ }^{-\bullet}$-based AOPs have been reported (Gao et al., 2019). Therefore, it is necessary to develop and apply an AOP for the effective removal of SMP in water.

Based on the above considerations, this study conducted an exploration on direct photolysis behavior of some SAs and photo-oxidative degradation of SMP in UV/Co(II)/PMS system. Furthermore, the toxicities of the main intermediates for SMP degradation in UV/Co(II)/PMS system to some aquatic organisms were predicted by using the ECOSAR program.

\section{Materials and Methods}

\subsection{Chemical Reagents}

Sulfamethoxazole (SMX, $\mathrm{C}_{10} \mathrm{H}_{11} \mathrm{~N}_{3} \mathrm{O}_{3} \mathrm{~S}, \quad 98 \%$ ), sulfadiazine ( $\mathrm{SDZ}, \mathrm{C}_{10} \mathrm{H}_{10} \mathrm{~N}_{4} \mathrm{O}_{2} \mathrm{~S} 99 \%$ ), sulfathiazole (STZ, $\quad \mathrm{C}_{9} \mathrm{H}_{9} \mathrm{~N}_{3} \mathrm{O}_{2} \mathrm{~S}_{2}, \quad 98.0 \%$ ), sulfapyridine (SPD, $\mathrm{C}_{11} \mathrm{H}_{11} \mathrm{~N}_{3} \mathrm{O}_{2} \mathrm{~S}$, 99\%), sulfamethizole (STZ2, $\mathrm{C}_{9} \mathrm{H}_{10} \mathrm{~N}_{4} \mathrm{O}_{2} \mathrm{~S}_{2},>98.0 \%$ ), sulfamerazine (SM1, $\mathrm{C}_{11} \mathrm{H}_{12} \mathrm{~N}_{4} \mathrm{O}_{2} \mathrm{~S},>98.0 \%$ ), sulfamethazine (SM2, $\mathrm{C}_{12} \mathrm{H}_{14} \mathrm{~N}_{4} \mathrm{O}_{2} \mathrm{~S},>98.0 \%$ ), sulfamonomethoxine (SMM, $\mathrm{C}_{11} \mathrm{H}_{12} \mathrm{~N}_{4} \mathrm{O}_{3} \mathrm{~S}, 95.0 \%$ ), sulfisoxazole (SIZ, $\mathrm{C}_{11} \mathrm{H}_{13} \mathrm{~N}_{3} \mathrm{O}_{3} \mathrm{~S}, 99 \%$ ), sulfamethoxypyridazine (SMP, $\mathrm{C}_{11} \mathrm{H}_{12} \mathrm{~N}_{4} \mathrm{O}_{3} \mathrm{~S}, 98 \%$ ) and sulfadimethoxine (SDM, $\mathrm{C}_{12} \mathrm{H}_{14} \mathrm{~N}_{4} \mathrm{O}_{4} \mathrm{~S}, 98 \%$ ) were provided by J\&K Chemical Reagent Co., Ltd (Beijing, China). tert-Butanol (TBA) and methanol $(\mathrm{MeOH})$ were also supplied by $\mathrm{J} \& \mathrm{~K}$ Chemical Ltd. Other chemicals used in this study such as peroxymonosulfate (PMS), $\mathrm{HCl}$ and $\mathrm{NaOH}$ were analytical reagent grade. All chemicals were used without further purification. Ultrapure water $(>18.2 \mathrm{M} \Omega \mathrm{cm})$ was prepared using a Milli-Q Plus system (Millipore, Bedford USA) throughout all experiments.

\subsection{Photodegradation Experiments}

All photodegradation experiments were carried out in an XPA-7 multi-tube agitated photochemical reactor (Xujiang Technology Co., Ltd. Nanjing, China), as displayed in Fig. S1 and in our previous work (Zeng et al., 2016). A $500 \mathrm{~W}$ Xe lamp or a $300 \mathrm{~W}$ medium 
pressure $\mathrm{Hg}$ lamp was employed as simulated sunlight source in direct photolysis experiments or as simulated UV light source in UV/Co(II)/PMS process, respectively. The emission spectra of used $\mathrm{Xe}$ and $\mathrm{Hg}$ lamps are also provided in Fig. S1. The light source was vertically placed inside a cylindrical quartz jacket with circulating water to cool the lamp, while the circulating water outside the jacket was used to keep the reaction temperature constant. To achieve uniform light exposure, the test reactive tubes were rotated by a merry-go-round apparatus within the photochemical reactor and the distance between the light source and the test tubes was $5 \mathrm{~cm}$. The light intensity at the sample position was about 48.0 and $4.15 \mathrm{~mW} \mathrm{~cm}^{-2}$ for Xe and $\mathrm{Hg}$ lamp, respectively.

The stock solution $\left(200 \mathrm{mg} \mathrm{L}^{-1}\right)$ prepared using ultrapure water was diluted to obtain the test solutions and the volume of used quartz reaction tube was $50 \mathrm{~mL}$. To simulate the conditions in natural water, the initial solution $\mathrm{pH}$ was adjusted to $7.0 \pm 0.1$ by $\mathrm{NaOH}$ and $\mathrm{HCl}$ solution except in the experiments involving the effects of $\mathrm{pH}$ on SMP degradation (unless particularly stated). At given time intervals, a $0.8 \mathrm{~mL}$ sample solution was extracted from the reaction solution and immediately quenched with $0.2 \mathrm{~mL}$ methanol for subsequent quantitative analysis. All photodegradation experiments were performed in triplicates and the results are presented as the mean value \pm standard deviation. It should be noted that the experiments involving the $\mathrm{pH}$ effects on SMP degradation were explored without buffer control.

\subsection{Analytical Methods}

The concentration of SMP and other SAs was analyzed employing an HPLC (Agilent Technologies, Series 1200) system equipped with a Aglient ZORBAX SB-C18 column $(5 \mu \mathrm{m}, 4.6 \times 150 \mathrm{~mm})$ and a UV detector. The used absorbance wavelengths for SMP and other SAs $(\lambda)$ were summarized in Table 1. A mixture of 50/50\% (V/V) methanol and acetonitrile was used as the mobile phase, and the flow rate was $0.5 \mathrm{~mL} \mathrm{~min}^{-1}$.

Based on the method proposed by Liang et al. (Liang et al., 2008), the remaining concentration of PMS at different reaction times was determined. Specifically, different volumes of PMS standard solutions and $250 \mu \mathrm{L}$ samples were respectively added
Table 1 The pseudo-first order rate constants for direct photolysis of SMP and other SAs and their some calculated molecular structure parameters

\begin{tabular}{llllll}
\hline SAs name & $\lambda(\mathrm{nm})$ & $\begin{array}{l}\text { Rate } \\
\text { constants } \\
\left(\mathrm{min}^{-1}\right)\end{array}$ & $R^{2}$ & $\Delta E($ a.u. $)$ & $L_{\mathrm{S}-\mathrm{N}}(\AA)$ \\
\hline SPD & 262 & 0.0005 & 0.9884 & 0.2639 & 1.653 \\
SDZ & 260 & 0.0006 & 0.9954 & 0.2539 & 1.657 \\
SM1 & 264 & 0.0007 & 0.9996 & 0.2573 & 1.658 \\
SM2 & 265 & 0.0006 & 0.9817 & 0.2606 & 1.656 \\
SMM & 265 & 0.0009 & 0.9818 & 0.2637 & 1.656 \\
SDM & 269 & 0.0017 & 0.9814 & 0.267 & 1.658 \\
STZ & 286 & 0.0014 & 0.9986 & 0.2646 & 1.662 \\
STZ2 & 255 & 0.0015 & 0.9970 & 0.2634 & 1.667 \\
SIZ & 270 & 0.0034 & 0.9463 & 0.2682 & 1.676 \\
SMX & 259 & 0.0030 & 0.9618 & 0.2702 & 1.663 \\
SMP & 254 & 0.0003 & 0.9974 & 0.2459 & 1.668 \\
\hline
\end{tabular}

into a solution containing $0.25 \mathrm{~g} \mathrm{NaHCO}_{3}$ and $5 \mathrm{~g}$ $\mathrm{KI}$, and the solution was diluted to $50 \mathrm{~mL}$. After standing for $15 \mathrm{~min}$, the absorbance of the above solutions was determined at $352 \mathrm{~nm}$ on a UV-vis spectrophotometer.

\subsection{Degradation Intermediates Identification}

The degradation intermediates of SMP in UV/Co(II)/ PMS system were analyzed by using LC/MS/MS technique and the employed instrument is a Waters Acquity UPLC system in tandem with a Waters Xevo G2-XS QToF Mass Spectrometer. An Acquity UPLC BEH C1 8 column $(1.7 \mu \mathrm{m}, 2.1 \times 50 \mathrm{~mm})$ was used to accomplish the separation. More detailed experimental parameters were described in our recent research report (Zeng et al., 2021).

\subsection{Toxicity Evaluation of Degradation Intermediates in UV/Co(II)/PMS System}

To evaluate the toxicity level of the intermediates for SMP degradation in UV/Co(II)/PMS system, the acute and chronic toxicities of these intermediates to fish, daphnids and green algae were predicted employing the ECOSAR program based on the globally harmonized system of classification and labeling of chemicals (GHSCLC). 


\subsection{Theoretical Calculation Methods}

To probe the essential causes of different rate constants for direct photolysis of SMP and other 10 SAs, a quantitative structure-activity relationship analysis was carried out based on the experimentally determined rate constants and the molecular structural parameters obtained by theoretical calculation. Specific calculation details are included in the supplementary data (Text S1). The structure and atomic numbering of SMP and other SAs are shown in Fig. S2. Table S1 lists the calculated values of all molecular structural descriptors.

\section{Results and Discussion}

\subsection{Direct Photodegradation Kinetics of SMP and Other 10 SAs}

Direct photolysis experiments of SMP and other 10 SAs (see Table 1) in aqueous solution were performed. The obtained results revealed that photolysis rates of the investigated sulfonamides are subject to the pseudo-first-order reaction kinetics model. According to the linear plot depicted in Eq. (1), the photolysis rate constants $\left(k_{\text {obs }}\right)$ can be derived.

$\ln \left(\mathrm{C} / \mathrm{C}_{0}\right)=-k_{\text {obs }} \mathrm{t}$

where $\mathrm{C}$ and $\mathrm{C}_{0}$ indicate the concentrations of sulfonamide reactants at any time and at the initial reaction time, respectively. The linear regression coefficients $\left(R^{2}\right)$ were found to be in the range of $0.9463 \sim 0.9996$, suggesting a good linearity. The derived rate constants of direct photolysis for 11 SAs and the corresponding correlation coefficient $\left(R^{2}\right)$ are listed in Table 1. We can see from Table 1 that the first-order rate constants for direct photolysis of $11 \mathrm{SAs}$ are all low and the values range from $0.0003 \mathrm{~min}^{-1}$ (for SMP) to $0.0034 \mathrm{~min}^{-1}$ (for SIZ). Moreover, based on the developed two-parameter optimal quantitative structure-activity relationship model $\left(\log k_{\mathrm{obs}}=-49.162+38.437 \Delta E+21.738 l_{\mathrm{S}-\mathrm{N}}\right)$, we found that the main factors affecting the direct photolysis rate of SAs are the energy differences between two frontier molecular orbitals $(\Delta \mathrm{E})$ and N-S bond length in SA molecules $\left(l_{\mathrm{S}-\mathrm{N}}\right)$. The differences between observed $\left(\log k_{\text {obs }}\right)$ and the predicted values $\left(\log k_{\text {pre }}\right)$ of the model are listed in Table S2. The plot of predicted $\left(\log k_{\mathrm{pre}}\right)$ versus observed $\left(\log k_{\mathrm{obs}}\right)$ values is shown in Fig. S3. Table S2 and Fig. S3 confirmed the linear character and good predictive ability of the obtained $\log k_{\text {obs }}$ model. The detailed discussion was displayed in the supplementary data (Text S2).

Compared with other selected SAs, SMP is the most difficult to be degradated under simulated sunlight. Thus, developing a more efficient way to remove SMP in aqueous solution is essential. However, it is critical to explore the optimal operational parameters for successful removal of polluants at a low cost. Thus, the optimal conditions for oxidation removal of SMP in UV/Co(II)/PMS system are discussed in detail below.

\subsection{Photodegradation of SMP in UV/Co(II)/PMS System}

\subsubsection{Effects of PMS and Co(II) Concentrations}

Batch experiments were conducted to establish the optimum concentration of PMS and Co(II) for efficient degradation of SMP in UV/Co(II)/PMS system. Firstly, five different molar concentrations of PMS were used to perform degradation experimentals. In all experiments, the initial $\mathrm{pH}$ was adjusted to $7.0 \pm 0.1$ using $0.1 \mathrm{M} \mathrm{HCl}$ and/or $0.1 \mathrm{M} \mathrm{NaOH}$, and SMP concentration is fixed at $20 \mathrm{mg} \mathrm{L}^{-1}$ $(0.071 \mathrm{mM})$. Figure $1 \mathrm{a}$ and $\mathrm{c}$ depicts the effect of different PMS concentrations on SMP degradation. Experimental results showed that when using UV alone, the removal rate of SMP is only $25.4 \%$ within 60 min irradiation time. When PMS with different concentrations was added into the reaction system, the removal efficiency of SMP was improved in different degrees. Increasing PMS concentration from 1.775 to $10.65 \mathrm{mM}$ showed an increase of the removal rate of SMP from 53.6 to $93.8 \%$ (Fig. 1a). However, when PMS concentration was further increased to $14.20 \mathrm{mM}$, the SMP removal rate was not significantly improved. Moreover, the degradation of SMP follows the pseudo-first-order rate equation, and the corresponding rate constants $\left(k_{\mathrm{obs}}\right)$ are displayed in Fig. 1c. When PMS concentration was varied from 1.775 to $14.20 \mathrm{mM}$, the $k_{\text {obs }}$ values changed in the range of $0.014 \sim 0.052 \mathrm{~min}^{-1}$, and the maximum value was observed at PMS concentration 
Fig. 1 Effects of PMS and $\mathrm{Co}(\mathrm{II})$ concentrations at $[\mathrm{SMP}]_{0}=0.071 \mathrm{mM}$ and initial $\mathrm{pH}=7.0$. a, $\mathbf{c}$ The degradation efficiency of SMP in UV/PMS system at different molar concentrations of PMS; $\mathbf{b}, \mathbf{d}$ the degradation efficiency of SMP in $\mathrm{UV} / \mathrm{Co}(\mathrm{II}) / \mathrm{PMS}$ system at different $\mathrm{Co}$ (II) dosage, $[\mathrm{PMS}]_{0}=10.65 \mathrm{mM}$ (the concentrations of SMP and PMS were fixed at initial molar ratio of 1:150); $\mathbf{e}$ PMS concentration of the measured samples as a function of time in the $\mathrm{UV} / \mathrm{PMS}$ and $\mathrm{UV} / \mathrm{Co}^{2+} /$ PMS systems, respectively. Experimental conditions: $[\mathrm{PMS}]_{0}=10.65 \mathrm{mM}$, initial $\mathrm{pH}=7.0$ and $\left[\mathrm{Co}^{2+}\right]=0.355 \mathrm{mM}$ (a)

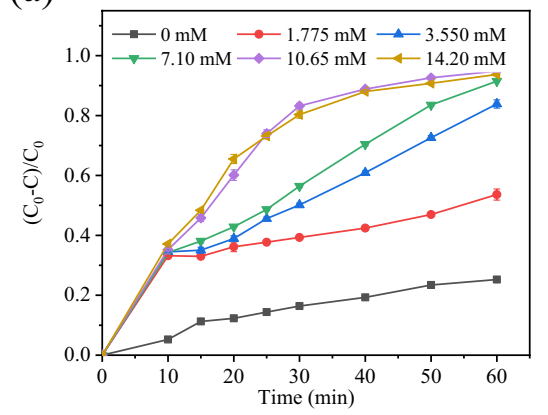

(c)

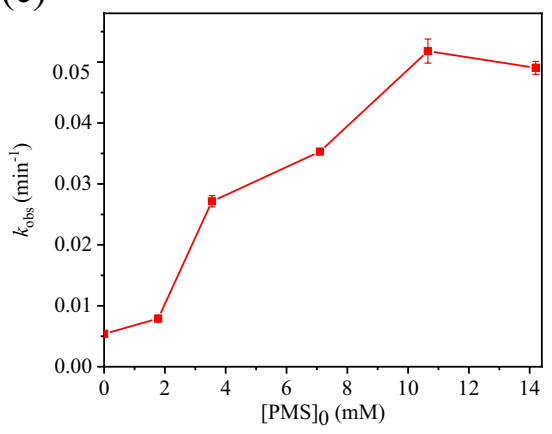

(b)

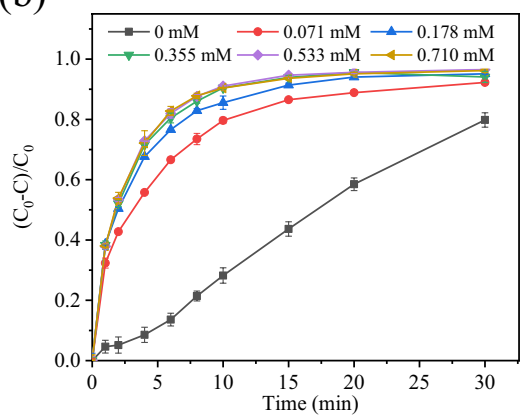

(d)

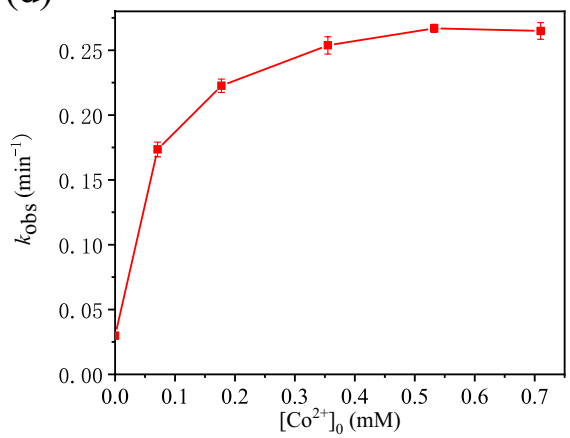

(e)

of $10.65 \mathrm{mM}$. This was probably because increasing PMS dosage could produce more $\mathrm{SO}_{4}{ }^{-\bullet}$ and $\mathrm{HO}^{\bullet}$ (Eq. (2)) and thus facilitate the degradation of SMP. However, extra dose of PMS could result in further secondary reactions (Eqs. (3)-(5)) (Khan et al., $2013,2016)$ and produce less-active $\mathrm{SO}_{5}{ }^{-\bullet}$ radicals, while $\mathrm{SO}_{5}{ }^{-\bullet}$ radicals can also react with each other, resulting in a decrease of the degradation efficiency of SMP. Thus the optimum molar ratio of SMP to PMS was 1:150 (which corresponds to $[\mathrm{SMP}]_{0}=0.071 \mathrm{mM}$ and $\left.[\mathrm{PMS}]=10.65 \mathrm{mM}\right)$ in the present study and was used in the follow-up experimental exploration.

$$
\begin{aligned}
& \mathrm{HSO}_{5}^{-}+\mathrm{hv} \rightarrow \mathrm{SO}_{4}^{-\bullet}+\mathrm{HO}^{\bullet} \\
& \mathrm{SO}_{4}^{-\cdot}+\mathrm{HSO}_{5}^{-} \rightarrow \mathrm{SO}_{5}^{-\cdot}+\mathrm{SO}_{4}^{2-}+\mathrm{H}^{+} \\
& \mathrm{HSO}_{5}^{-}+\mathrm{HO}^{-} \rightarrow \mathrm{SO}_{5}^{-\bullet}+\mathrm{OH}^{-} \\
& \mathrm{SO}_{4}^{-\cdot}+\mathrm{SO}_{4}^{-\cdot} \rightarrow \mathrm{S}_{2} \mathrm{O}_{8}^{2-}
\end{aligned}
$$

To further improve the efficiency for SMP degradation, transition metal Co(II) coupled with UV light was selected to co-activate PMS. Batch experiments 
were also performed to assess the influence of $\mathrm{Co}$ (II) dose on photolysis of SMP. Figure $1 \mathrm{~b}$ and d depicts the efficiency for SMP degradation using UV/Co(II)/PMS system at different concentrations of $\mathrm{Co}$ (II), where the initial concentrations of SMP and PMS were fixed at $0.071 \mathrm{mM}$ and $10.65 \mathrm{mM}$, respectively. As indicated in Fig. 1b, when the concentration of Co(II) was increased from 0 to $0.355 \mathrm{mM}$, the removal rate of SMP increases sharply from 58.4 to $95.2 \%$ after $20 \mathrm{~min}$ of reaction, and the corresponding rate constants increased from 0.0298 to $0.2562 \mathrm{~min}^{-1}$ (Fig. 1d). However, as the concentration of $\mathrm{Co}$ (II) was further increased, the degradation efficiency of SMP hardly increased. Thus the optimum molar ratio of SMP, PMS and Co(II) was 1:150:5 (corresponding to $[\mathrm{SMP}]_{0}=0.071 \mathrm{mM},[\mathrm{PMS}]=10.65 \mathrm{mM}$ and $[\mathrm{Co}(\mathrm{II})]=0.355 \mathrm{mM})$ in the current work. In addition, the advantageous synergistic effect of $\mathrm{Co}$ (II) and UV light was observed in SMP removal in an aqueous solution. The result is similar to that of the previous studies on the degradation of 2,3,7,8-tetrachlorinated dibenzo-p-dioxins (TeCDD) in UV/Fe(II)/PMS (Zeng et al., 2017) and UV/Fe(II)/ $/ \mathrm{H}_{2} \mathrm{O}_{2}$ (Wang et al., 2019) systems. The synergistic effect could be due to the ability of both Co(II) and UV light to activate PMS in generating reactive radicals (Eqs. (2) and (6)-(8)) (Xu et al., 2020). To better understand the activation potential of Co(II) for PMS oxidation of SMP, the remaining concentrations of PMS in the reaction solutions were determined and shown in Fig. 1e. As compared with the system using only UV to activate PMS, PMS was decomposed at a significantly accelerated rate in the UV/Co(II)/PMS system. For example, only $4.7 \%$ PMS was decomposed after $10 \mathrm{~min}$ of degradation in the UV/PMS system, while 95.2\% PMS was consumed after $10 \mathrm{~min}$ of reaction in the UV/Co(II)/PMS system, which was consistent with much higher removal rates of SMP in the UV/Co(II)/PMS system. Therefore, we can infer that $\mathrm{Co}$ (II) can activate PMS more remarkably than UV to produce more radicals and consequently accelerate the removal of SMP. The above results suggested that SMP can be degraded efficiently in aqueous solution using UV/Co(II)/PMS system. The optimal concentration ratio of SMP, PMS and Co(II) was used in further experimental investigation.

$$
\begin{aligned}
& \mathrm{C}_{\mathrm{O}}^{2+}+\mathrm{HSO}_{5}^{-} \rightarrow \mathrm{C}_{\mathrm{O}}^{3+}+\mathrm{SO}_{4}^{-\cdot}+\mathrm{HO}^{-} \\
& \mathrm{C}_{\mathrm{O}}^{3+}+\mathrm{HSO}_{5}^{-} \rightarrow \mathrm{C}_{\mathrm{O}}^{2+}+\mathrm{SO}_{5}^{-\cdot}+\mathrm{H}^{+}
\end{aligned}
$$

$\mathrm{SO}_{4}^{-\bullet}+\mathrm{HO}^{-}$orH $_{2} \mathrm{O} \rightarrow \mathrm{HO}^{\bullet}$

\subsubsection{Effect of Initial $\mathrm{pH}$}

The $\mathrm{pH}$ of the reaction solution may have a significant influence on the behavior of free radical species and it can impact the performance of UV/Co(II)/PMS system. Thus, the effect of the initial $\mathrm{pH}$ of solution on SMP degradation in UV/Co(II)/PMS system was investigated. Figure 2 shows SMP degradation efficiency at different $\mathrm{pH}$, and the highest degradation rate of SMP appeared at $\mathrm{pH}$ of 9 and it reached almost $100 \%$ in 30 min. The SMP degradation efficiency showed an irregular variation trend when the initial $\mathrm{pH}$ changes from 3 to 11 , and it varied slightly in the $\mathrm{pH}$ range of 5 to 7 . However, the degradation rate of SMP was only $42.3 \%$ at $\mathrm{pH}=11$. These results indicated that SMP was degraded more efficiently under weakly acidic or alkaline conditions, which can be explained based on the existing form of SMP in aqueous solution and the amount of radical species that directly cause the degradation of SMP. Since both acidic amide group $(-\mathrm{NH}-)$ and basic amine group $\left(-\mathrm{NH}_{2}\right)$ occur simultaneously in SMP molecule with $\mathrm{p} K_{\mathrm{a} 1}=2.2$ and $\mathrm{p} K_{\mathrm{a} 2}=7.2$, it can exist in cationic, neutral, and anionic forms in aqueous solution. Obviously, as the $\mathrm{pH}$ of the aqueous solution gradually increases, the relative content of the anionic form in

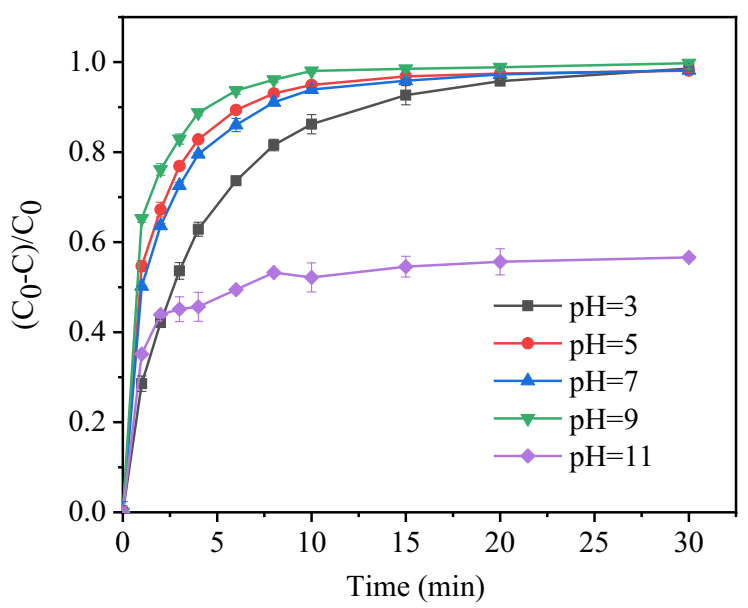

Fig. 2 The degradation efficiency of SMP in UV/Co(II)/ PMS system at different initial $\mathrm{pH}$, the ratio of SMP, PMS and $\mathrm{Co}$ (II) was fixed at an initial molar ratio of 1:150:5 $\left([\mathrm{SMP}]_{0}=0.071 \mathrm{mM}\right)$ 
the three existing forms of SMP gradually increases, and it dominates in alkaline solution. As illustrated in our recent research (Zeng et al., 2020), the anionic form of SMP should be more reactive toward $\mathrm{HO}^{\bullet}$ than its other forms. So it can reasonably be inferred that SMP is more easily degraded in alkaline solutions. Moreover, the molar absorption coefficient of PMS in aqueous solution substantially increases with increasing $\mathrm{pH}$, which lead to an increase in the amount of radical species. However, the sharp decrease of reactivity of $\mathrm{Co}$ (II) by the appearance of precipitation at strongly alkaline conditions may lead to an obvious reduction in the amount of radical species. Therefore, the combined effect of these factors results in the highest degradation efficiency of SMP at $\mathrm{pH}=9$.

\subsubsection{Effects of Coexisting Inorganic Ions on SMP Degradation}

Coexisting inorganic ions in water bodies affect the oxidation degradation process of the target pollutants because they have significant impacts on the speciation concentration of reactive oxidants (Lei et al., 2020; $\mathrm{Xu}$ et al., 2020). Thus, water bodies components such as $\mathrm{Cl}^{-}, \mathrm{CO}_{3}{ }^{2-}, \mathrm{HCO}_{3}{ }^{-}$and $\mathrm{HPO}_{4}{ }^{2-}$ were selected to study their effects on SMP removal by the $\mathrm{UV} / \mathrm{Co}(\mathrm{II}) / \mathrm{PMS}$ oxidation. The concentrations of 2 and $10 \mathrm{mM}$ for $\mathrm{Cl}^{-}, \mathrm{CO}_{3}{ }^{2-}, \mathrm{HCO}_{3}{ }^{-}$and $\mathrm{HPO}_{4}{ }^{2-}$ were used to carry out the experiments. The experimental results are depicted in Fig. 3. As shown in Fig. 3a, $\mathrm{Cl}^{-}$has adverse effect on SMP degradation, and the inhibition of SMP degradation became more obvious as the $\mathrm{Cl}^{-}$level increases. The possible reason is that highly reactive sulfate radicals were transformed into less reactive chlorine species such as $\mathrm{Cl}^{\bullet}, \mathrm{HOCl}, \mathrm{Cl}_{2}$, and $\mathrm{Cl}_{2}{ }^{\bullet-}$ by $\mathrm{Cl}^{-}$according to the following reactions (Eqs. (9)-(12)). Similar trend has also been reported by Sharma et al. for oxidation degradation of Bisphenol A using UV-C/PMS system (Sharma et al., 2015).

$$
\begin{aligned}
& \mathrm{SO}_{4}^{-\bullet}+\mathrm{Cl}^{-} \rightarrow \mathrm{SO}_{4}^{2-}+\mathrm{Cl}^{\bullet} \\
& \mathrm{Cl}^{\bullet}+\mathrm{Cl}^{-} \leftrightarrow \mathrm{Cl}_{2} \\
& \mathrm{Cl}_{2}^{--}+\mathrm{Cl}_{2}^{--} \rightarrow 2 \mathrm{Cl}^{-}+\mathrm{Cl}_{2}
\end{aligned}
$$

$$
\mathrm{Cl}_{2}+\mathrm{H}_{2} \mathrm{O} \rightarrow \mathrm{HOCl}+\mathrm{Cl}^{-}+\mathrm{H}^{+}
$$

Figure $4 \mathrm{~b}$ and $\mathrm{c}$ shows that SMP degradation was not obviously influenced by $\mathrm{CO}_{3}{ }^{2-}$ and $\mathrm{HCO}_{3}{ }^{-}$with a low concentration of $2 \mathrm{mM}$. However, the stronger inhibition of SMP degradation was observed at higher concentrations of $\mathrm{CO}_{3}{ }^{2-}$ and $\mathrm{HCO}_{3}{ }^{-}$ions $(10 \mathrm{mM})$. This is because $\mathrm{HCO}_{3}{ }^{-}$and $\mathrm{CO}_{3}{ }^{2-}$ can quench hydroxyl radicals and sulfate radicals via the reactions shown in Eqs.(13)-(16) (Ao \& Liu, 2017). Thus $\mathrm{HCO}_{3}{ }^{-}$and $\mathrm{CO}_{3}{ }^{2-}$ with higher concentrations $(10 \mathrm{mM})$ would have a significant negative effect on SMP removal.

$$
\begin{aligned}
& \mathrm{SO}_{4}^{-\bullet}+\mathrm{HCO}_{3}^{-} \rightarrow \mathrm{SO}_{4}^{2-}+\mathrm{CO}_{3}^{-\bullet} \\
& \mathrm{HO}+\mathrm{HCO}_{3}^{-} \rightarrow \mathrm{H}_{2} \mathrm{O}+\mathrm{CO}_{3}^{-\bullet} \\
& \mathrm{SO}_{4}^{-\bullet}+\mathrm{CO}_{3}^{2-} \rightarrow \mathrm{SO}_{4}^{2-}+\mathrm{CO}_{3}^{-\bullet} \\
& \mathrm{HO}^{-}+\mathrm{CO}_{3}^{2-} \rightarrow \mathrm{HO}^{-}+\mathrm{CO}_{3}^{-\bullet}
\end{aligned}
$$

By comparing the result in Fig. $3 b$ with that in Fig. 3c, we can see that the inhibitory effect of $\mathrm{CO}_{3}{ }^{2-}$ with a concentration of $10 \mathrm{mM}$ on SMP degradation is greater than that of $\mathrm{HCO}_{3}{ }^{-}$with the same concentration. For example, the degradation rate of SMP after $30 \mathrm{~min}$ of reaction dropped from $97.2 \%$ (UV/Co(II)/PMS alone) to $63.1 \%$ or $74.1 \%$ in presence of $\mathrm{CO}_{3}{ }^{2-}$ or $\mathrm{HCO}_{3}{ }^{-}$, respectively. This may be due to the increase in $\mathrm{pH}$ caused by the reaction between $\mathrm{HO}^{\bullet}$ and $\mathrm{CO}_{3}{ }^{2-}$ as shown in Eq. (16). It was reported that $\mathrm{HPO}_{4}{ }^{2-}$ has the ability to activate PMS (Lou et al., 2014). However, as shown in Fig. 3d, lowdosage $\mathrm{HPO}_{4}{ }^{2-}(2 \mathrm{mM}$ and $10 \mathrm{mM})$ may have only a limited activation ability in the current study. This implies that the role of $\mathrm{HPO}_{4}{ }^{2-}$ may be related to the type of reaction substrates and reaction conditions.

\subsubsection{The Contribution of Radical Species to Oxidative Degradation of SMP}

In order to confirm the contribution of radical species for SMP degradation, radical scavenging tests were performed by adding two radical scavengers including tert-butyl alcohol (TBA) and methanol (MeOH) into the reaction solution, separately. TBA and $\mathrm{MeOH}$ were usually utilized as effective scavengers 
(a)

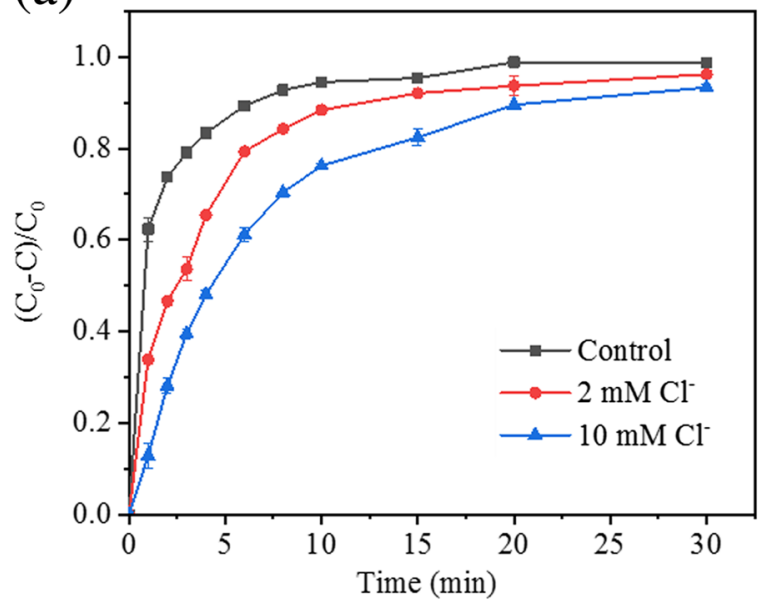

(c)

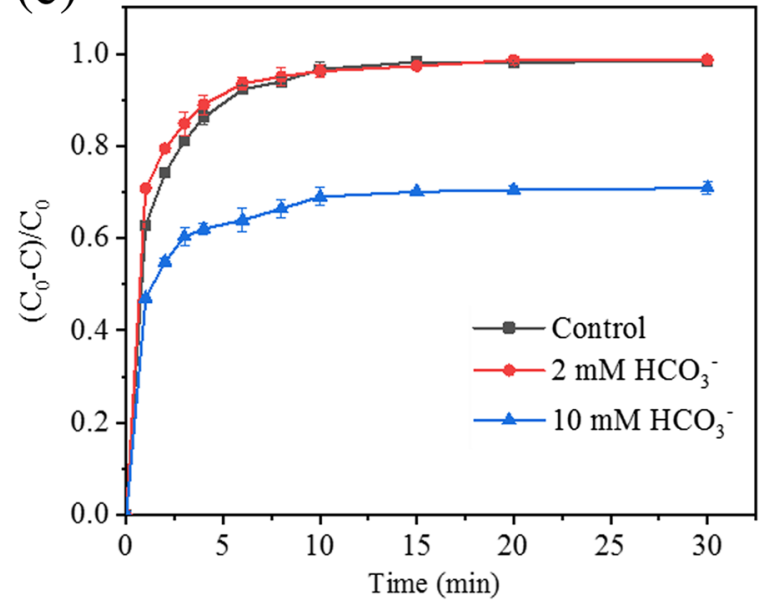

Fig. 3 Effects of inorganic anions on oxidative degradation of SMP in UV/Co(II)/PMS system, a $\mathrm{Cl}^{-}, \mathbf{b} \mathrm{CO}_{3}{ }^{2-}$, c $\mathrm{HCO}_{3}{ }^{-}$, and $\mathbf{d} \mathrm{H}_{2} \mathrm{PO}_{4}{ }^{-}$. The experimental conditions

to distinguish the contribution of $\mathrm{HO}^{\bullet}$ and $\mathrm{SO}_{4}{ }^{-\bullet}$ based on the following Eqs. (17)-(20). $\mathrm{MeOH}$ is considered as an effective quencher for both $\mathrm{SO}_{4}^{-\bullet}$ and $\mathrm{HO}^{\bullet}$ since the two scavenging reactions between $\mathrm{MeOH}$ and $\mathrm{SO}_{4}^{-\bullet}$ or $\mathrm{HO}^{\bullet}$ (Eqs. (17)-(18)) are both fast (Xie et al., 2015). However, TBA is only an effective quenching agent for $\mathrm{HO}^{\circ}$, because the rate constant for the reaction between TBA and $\mathrm{SO}_{4}{ }^{-\bullet}$ is much smaller than that between TBA and $\mathrm{HO}^{\bullet}$ (Eqs. (19)-(20)). Therefore, the difference of inhibition effects of $\mathrm{MeOH}$ and TBA on SMP degradation can be used to identify the contribution of $\mathrm{HO}^{\bullet}$ and $\mathrm{SO}_{4}{ }^{-\bullet}$ in the current reaction system. (b)

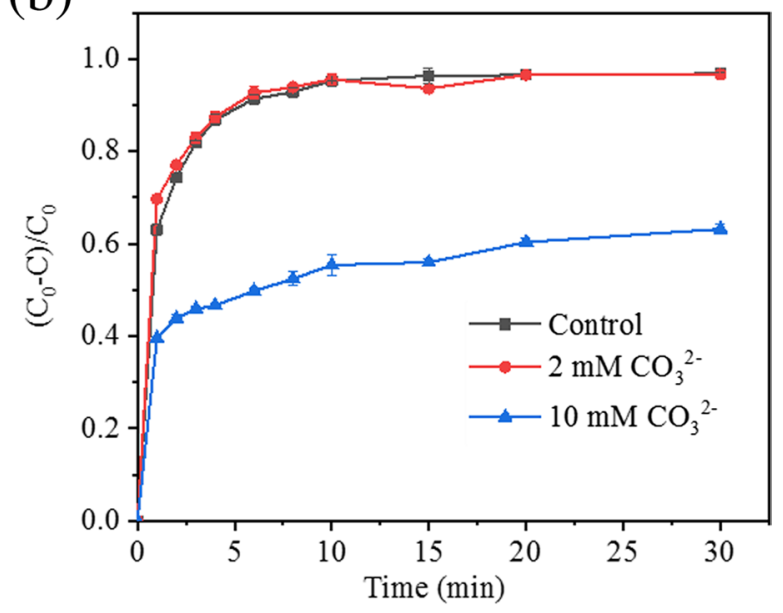

(d)

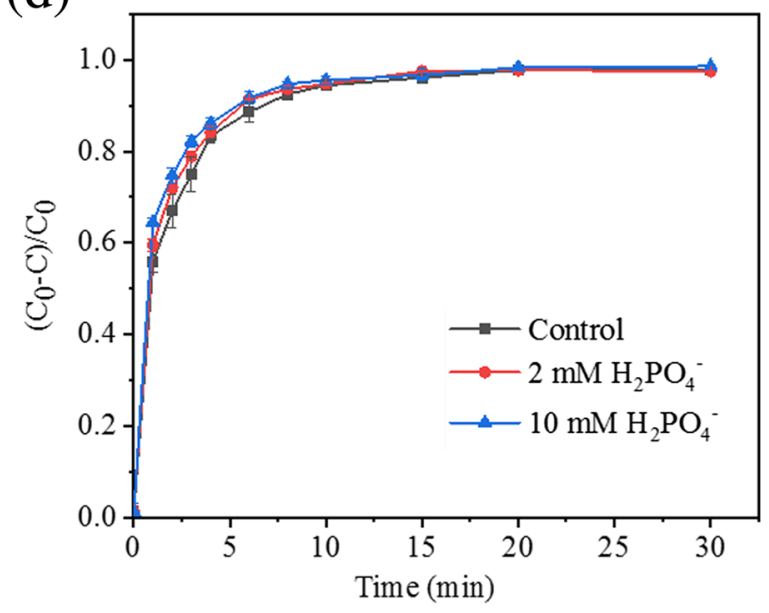

are as follows: $[\mathrm{SMP}]_{0}=0.071 \mathrm{mM},[\mathrm{PMS}]_{0}=10.65 \mathrm{mM}$, $\left[\mathrm{Co}^{2+}\right]_{0}=0.355 \mathrm{mM}$ and initial $\mathrm{pH}=7.0$

$\mathrm{HO}^{\bullet}+\mathrm{MeOH} \rightarrow$ products $k=9.7 \times 10^{8} \mathrm{M}^{-1} s^{-1}$

$\mathrm{SO}_{4}^{-\bullet}+\mathrm{MeOH} \rightarrow$ products $k=1.1 \times 10^{7} \mathrm{M}^{-1} \mathrm{~s}^{-1}$

$\mathrm{HO}^{\bullet}+\mathrm{TBA} \rightarrow$ products $\mathrm{k}=6.0 \times 10^{8} \mathrm{M}^{-1} \mathrm{~s}^{-1}$

$\mathrm{SO}_{4}^{-\bullet}+\mathrm{TBA} \rightarrow$ products $k=4 \times 10^{5} \mathrm{M}^{-1} \mathrm{~s}^{-1}$

As shown in Fig. 4, when two concentrations (7.1 and $142 \mathrm{mM}$ ) of $\mathrm{MeOH}$ or TBA were introduced into the reaction solution, significant inhibition was 


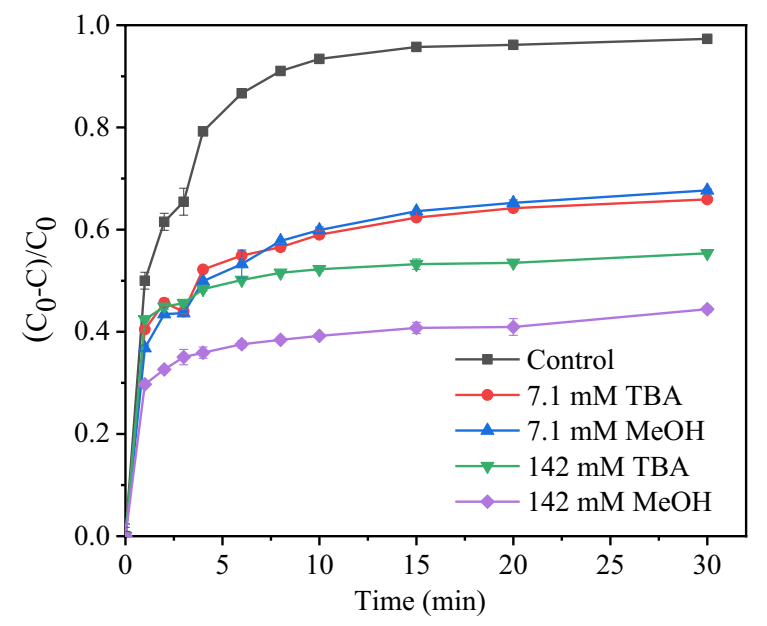

Fig. 4 The result of radical scavenging tests for oxidative degradation of SMP in UV/Co(II)/PMS system. Experimental conditions: SMP: PMS: $\mathrm{Co}(\mathrm{II})=1: 150: 5,[\mathrm{SMP}] 0=0.071 \mathrm{mM}$, $\mathrm{pH}=9.0$

observed for SMP degradation. Moreover, Fig. 4 indicated that the more $\mathrm{MeOH}$ or TBA were added, the stronger its inhibition effect on SMP degradation was. Specifically, about $98 \%$ SMP degradation was achieved after $30 \mathrm{~min}$ reaction without scavengers, whereas SMP degradation rates were declined to $65.9 \%$ or $67.6 \%$ with the addition of $7.1 \mathrm{mM} \mathrm{MeOH}$ or TBA, respectively. The degradation rate of SMP after 30 min reaction was declined to $44.4 \%$ or $55.4 \%$ with the addition of $142 \mathrm{mM} \mathrm{MeOH}$ or TBA, respectively. These results showed that the inhibiting degree of $\mathrm{MeOH}$ on SMP degradation is higher than that of TBA, which suggests that although both $\mathrm{SO}_{4}{ }^{-\bullet}$ and $\mathrm{HO}^{\bullet}$ were produced in UV/Co(II)/PMS system, $\mathrm{HO}^{\bullet}$ played a leading role in SMP degradation at $\mathrm{pH}$ of 9. Zhang et al. (2019) also found that $\mathrm{HO}^{\bullet}$ was the dominant radical in the degradation of haloacetonitriles with UV/PMS process.

\subsubsection{Identification of Intermediates and Possible Degradation Pathways}

MS/MS technique was employed to determine the main intermediates for SMP degradation in UV/ Co(II)/PMS system. Eight plausible intermediates were detected based on the obtained MS data in the positive mode, and their suggested molecular formulas and the corresponding fragmentation patterns are indicated in Fig. S4.
Based on the molecular structures of eight intermediates, four plausible pathways for SMP degradation in UV/Co(II)/PMS system were suggested and shown in Fig. 5. According to pathway $\mathrm{I}, \mathrm{HO}^{\bullet}$ attacks $\mathrm{C}$ atoms on the benzene or pyridazine rings firstly to give monohydroxylated intermediate P1 with a $\mathrm{m} / \mathrm{z}$ of 297.06, and then the amino group on the benzene ring of P1 was oxidized to nitro group, affording the intermediated P2 with a $\mathrm{m} / \mathrm{z}$ of 327.03 . It should be noted that the formation of $\mathrm{P} 1$ can also be accomplished by initial attack of $\mathrm{SO}_{4}{ }^{-\bullet}$ on the aromatic ring of SMP via direct electron transfer to form radical cations and the subsequent hydrolysis process. Moreover, according to our previous theoretical investigation on $\mathrm{HO}^{\bullet}$ addition reactions of three sulfonamides (Zeng et al., 2020), benzene ring may be more advantageous positions for $\mathrm{HO}^{\bullet}$ addition of neutral sulfonamides than corresponding heterocycles. In the pathway II, the extraction of $\mathrm{SO}_{2}$ from SMP leads to formation of the intermediate P3 with a $\mathrm{m} / \mathrm{z}$ of 217.70. Subsequent oxidation or elimination of aniline moiety in P3 can give intermediate $\mathrm{P} 4$ or P5. In the pathway III, direct oxidation of aniline moiety in SMP can lead to the formation of intermediate P6 with a $\mathrm{m} / \mathrm{z}$ of 311.04 . Pathway IV involves the breakage of $\mathrm{N}-\mathrm{S}$ bond, resulting in the formation of intermediate $\mathrm{P} 7$ with a $\mathrm{m} / \mathrm{z}$ of 126.06. Subsequent oxidation of amino group in P7 can produce intermediate P8. The above four degradation pathways were also identified in a previous research involving SMP degradation in the UV/ PS system (Gao et al., 2019).

\subsubsection{Prediction of Toxicities for SMP and the Degradation Intermediates}

Based on the globally harmonized system of classification and labeling of chemicals (GHSCLC), acute and chronic toxicities of SMP and the intermediates for SMP degradation in UV/Co(II)/PMS system (P1 P8) to fish, daphnids, and green algae were predicted employing ECOSAR program, and the obtained data are listed in Table 2 . We can see from Table 2 that the chronic toxicities of SMP and P1 P8 to three aquatic organisms are more significant than their acute toxicities. Moreover, they show stronger acute toxicities to daphnid and green algae than to fish in general, while they have more remarkable chronic toxicities to fish and daphnid. Compared with SMP, although P1 and P8 are less toxic, P3 and P7 
<smiles>COc1ccc([N+](=O)[O-])nn1</smiles>

P8 (m/z 156.04)<smiles>C=[Tl]</smiles>

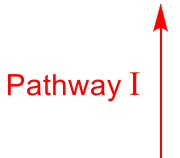<smiles>COc1ccc(N)nn1</smiles>

P7 (m/z 126.06) SMP $(\mathrm{m} / \mathrm{z} 281.07)$ $\mathrm{NH}_{2}$ P3 $(\mathrm{m} / \mathrm{z} 217.10)$<smiles>COc1ccc(NS(=O)(=O)c2ccc([N+](=O)[O-])cc2)nn1</smiles>

Fig. 5 Proposed degradation pathways of SMP in UV/Co(II)/PMS system

Table 2 Predicted acute and chronic toxicities of SMP and the intermediates for SMP degradation by the ECOSAR program

\begin{tabular}{ccccccc}
\hline Compound & \multicolumn{3}{c}{ Acute toxicity $\left(\mathbf{m g ~ L}^{-\mathbf{1}}\right)$} & \multicolumn{3}{c}{ Chronic toxicity $\left.\mathbf{( m g ~ L ~}^{-\mathbf{1}}\right)$} \\
\hline & Fish & Daphnid & Green algae & Fish & Daphnid & Green algae \\
& $(\mathrm{LC} 50) / 96 \mathrm{~h}$ & $(\mathrm{LC} 50) / 48 \mathrm{~h}$ & $(\mathrm{EC} 50) / 96 \mathrm{~h}$ & $\mathrm{ChV}$ & $\mathrm{ChV}$ & $\mathrm{ChV}$ \\
SMP & 719 & 2.08 & 8.56 & 4.14 & 0.12 & 13.1 \\
P1 & 1642 & 2.23 & 11.8 & 9.67 & 0.17 & 17.2 \\
P2 & 31.3 & 2.51 & 13.2 & 2.15 & 1.15 & 2.11 \\
P3 & 118 & 1.58 & 3.89 & 0.65 & 0.046 & 6.54 \\
P4 & 67 & 40 & 36 & 6.9 & 4.4 & 10.5 \\
P5 & 45 & 27 & 25 & 4.7 & 3.1 & 7.6 \\
P6 & 537 & 967 & 13.4 & 0.49 & 26.8 & 8.04 \\
P7 & 226 & 0.93 & 3.39 & 1.29 & 0.044 & 5.30 \\
P8 & 4342 & 2111 & 1526 & 352 & 132 & 151
\end{tabular}

Green: Not harmful. LC50/EC50/ChV $>100 \mathrm{mg} \mathrm{L}^{-1}$.

Blue: Harmful. $10 \mathrm{mg} \mathrm{L}^{-1}<\mathrm{LC} 50 / \mathrm{EC} 50 / \mathrm{ChV} \leq 100 \mathrm{mg} \mathrm{L}^{-1}$.

Purple: Toxic. $1 \mathrm{mg} \mathrm{L}^{-1}<\mathrm{LC} 50 / \mathrm{EC} 50 / \mathrm{ChV} \leq 10 \mathrm{mg} \mathrm{L}^{-1}$.

Red: Very toxic. LC50/EC50/ChV $\leq 1 \mathrm{mg} \mathrm{L}^{-1}$. 
have stronger toxicities. As for P2, P4, P5, and P6, the situation is much more complex, and their acute and chronic toxicities are distributed divergently. It should be noted that P8 does not exhibit any acute or chronic toxicity to three aquatic organisms in all intermediates, and is even harmless to them. In a word, SMP and its degradation intermediates in the UV/Co(II)/ PMS system could be classified to different toxicity levels. Therefore, both the removal rate of SMP and the toxicities of degradation intermediates should be considered in SMP degradation by UV/Co(II)/PMS system.

\section{Conclusions}

The direct photodegradation of SMP under simulated sunlight followed pseudo first-order kinetics and was the slowest compared with other selected SAs. So UV/Co(II)/PMS system was employed as an AOP to remove SMP in an aqueous solution. The obtained results showed that SMP could be effectively degraded in UV/Co(II)/ PMS system. The optimal reaction conditions are [SMP]:[PMS]:[Co(II)] = 1:150:5 (molar ratio) and $\mathrm{pH}$ 9.0. The observed degradation rate constants are dependent on the concentrations of $\mathrm{Co}^{2+}$ and PMS. The presence of coexisting inorganic anions such as $\mathrm{Cl}^{-}, \mathrm{CO}_{3}{ }^{2-}$, and $\mathrm{HCO}_{3}{ }^{-}$showed a negative effect on SMP degradation. Scavenging experiments showed that $\mathrm{HO}^{\bullet}$ played a major role in SMP degradation under mildly alkaline conditions $(\mathrm{pH}=9.0)$. Hydroxylation of the aromatic ring, extrusion of $\mathrm{SO}_{2}$, oxidation of $\mathrm{NH}_{2}$ group and $\mathrm{N}-\mathrm{S}$ bond cleavage were primary pathways for aqueous SMP degradation in UV/Co(II)/PMS system. The intermediates involved in SMP degradation show divergent toxicity distribution. It can be concluded that the technology utilizing $\mathrm{UV}$ and $\mathrm{Co}^{2+}$ to activate PMS is an effective approach for SMP removal in an aqueous solution.

\footnotetext{
Author Contribution $\mathrm{XZ}$ conceived and designed the study, supervised the experiment execution, carried out the theoretical calculations, and reviewed and edited the manuscript. XS conceived and designed the study, performed the experiments, and wrote the paper. YM performed the experiments. NY performed the experiments. JL performed the experiments. All authors read and approved the final manuscript.
}

Funding This work was funded by the National Natural Science Foundation of China (Grant No. 21876143), Key Scientific Research Projects of Universities in Henan Province (Grant No. 19B610003), and Nanhu Scholars Program for Young Scholars of XYNU.

Data Availability All data generated or analyzed during this study are included in this published article and its supplementary information files.

Code Availability Not applicable.

\section{Declarations}

Ethics approval Not applicable.

Consent to participate Not applicable.

Consent for publication Not applicable.

Competing interests The authors declare that they have no competing interests.

\section{References}

Al-Maqdi, K. A., Hisaindee, S., Rauf, M. A., \& Ashraf, S. S. (2018). Detoxification and degradation of sulfamethoxazole by soybean peroxidase and $\mathrm{UV}+\mathrm{H}_{2} \mathrm{O}_{2}$ remediation approaches. Chemical Engineering Journal, 352, 450458. https://doi.org/10.1016/j.cej.2018.07.036

Ao, X., \& Liu, W. (2017). Degradation of sulfamethoxazole by medium pressure UV and oxidants: Peroxymonosulfate, persulfate, and hydrogen peroxide. Chemical Engineering Journal, 313, 629-637. https://doi.org/10.1016/j.cej.2016. 12.089

Batista, A. P. S., Teixeira, A. C. S. C., Cooper, W. J., \& Cottrell, B. A. (2016). Correlating the chemical and spectroscopic characteristics of natural organic matter with the photodegradation of sulfamerazine. Water Research, 93, 20-29. https://doi.org/10.1016/j.watres.2015.11.036

Dong, H., Yuan, X., Wang, W., \& Qiang, Z. (2016). Occurrence and removal of antibiotics in ecological and conventional wastewater treatment processes: A field study. Journal of Environmental Management, 178, 11-19. https:// doi.org/10.1016/j.jenvman.2016.04.037

Du, L., Xu, W., Liu, Y., Li, X., Huang, d., \& Wu, S. (2020). Removal of sulfamethoxazole in aqueous solutions by iron-based advanced oxidation processes: Performances and mechanisms. Water Air and Soil Pollution. 231, 159. https://doi.org/10.1007/s11270-020-04534-w

Feng, M., Cizmas, L., Wang, Z., \& Sharma, V. K. (2017). Synergistic effect of aqueous removal of fluoroquinolones by a combined use of peroxymonosulfate and ferrate(VI). Chemosphere, 177, 144-148. https://doi.org/10.1016/j. chemosphere.2017.03.008 
Gao, Y., Gao, N., Chu, W., Zhang, Y., Zhang, J., \& Yin, D. (2019). UV-activated persulfate oxidation of sulfamethoxypyridazine: Kinetics, degradation pathways and impact on DBP formation during subsequent chlorination. Chemical Engineering Journal, 370, 706-715. https://doi. org/10.1016/j.cej.2019.03.237

Hori, H., Nagano, Y., Murayama, M., Koike, K., \& Kutsuna, S. (2012). Efficient decomposition of perfluoroether carboxylic acids in water with a combination of persulfate oxidant and ultrasonic irradiation. Journal of Fluorine Chemistry, 141, 5-10. https://doi.org/10.1016/j.jfluchem. 2012.05.012

Khan, J. A., He, X., Khan, H. M., Shah, N. S., \& Dionysiou, D. D. (2013). Oxidative degradation of atrazine in aqueous solution by $\mathrm{UV} / \mathrm{H}_{2} \mathrm{O}_{2} / \mathrm{Fe}^{2+}, \mathrm{UV} / \mathrm{S}_{2} \mathrm{O}_{8}{ }^{2-} / \mathrm{Fe}^{2+}$ and $\mathrm{UV} /$ $\mathrm{HSO}_{5}{ }^{-} / \mathrm{Fe}^{2+}$ processes: A comparative study. Chemical Engineering Journal, 218, 376-383. https://doi.org/10. 1016/j.cej.2012.12.055

Khan, S., He, X., Khan, H. M., Boccelli, D., \& Dionysiou, D. D. (2016). Efficient degradation of lindane in aqueous solution by iron (II) and/or UV activated peroxymonosulfate. Journal of Photochemistry and Photobiology A: Chemistry, 316, 37-43. https://doi.org/10.1016/j.jphot ochem.2015.10.004

Kong, D., Liang, B., Yun, H., Cheng, H., Ma, J., Cui, M., Wang, A., \& Ren, N. (2015). Cathodic degradation of antibiotics: Characterization and pathway analysis. Water Research, 72, 281-292. https://doi.org/10.1016/j.watres. 2015.01.025

Lapworth, D. J., Baran, N., Stuart, M. E., \& Ward, R. S. (2012). Emerging organic contaminants in groundwater: A review of sources, fate and occurrence. Environmental Pollution, 163, 287-303. https://doi.org/10.1016/j.envpol. 2011.12.034

Lei, Y., Lu, J., Zhu, M., Xie, J., Peng, S., \& Zhu, C. (2020). Radical chemistry of diethyl phthalate oxidation via UV/ peroxymonosulfate process: Roles of primary and secondary radicals. Chemical Engineering Journal, 379, 122339. https://doi.org/10.1016/j.cej.2019.122339

Liang, C., Huang, C., Mohanty, N., \& Kurakalva, R. M. (2008). A rapid spectrophotometric determination of persulfate anion in ISCO. Chemosphere, 73, 1540-1543. https://doi. org/10.1016/j.chemosphere.2008.08.043

Liu, X., Liu, Y., Lu, S., Guo, W., \& Xi, B. (2018). Performance and mechanism into $\mathrm{TiO}_{2} /$ Zeolite composites for sulfadiazine adsorption and photodegradation. Chemical Engineering Journal, 350, 131-147. https://doi.org/10.1016/j. cej.2018.05.141

Lou, X., Wu, L., Guo, Y., Chen, C., Wang, Z., Xiao, D., Fang, C., Liu, J., Zhao, J., \& Lu, S. (2014). Peroxymonosulfate activation by phosphate anion for organics degradation in water. Chemosphere, 117, 582-585. https://doi.org/10. 1016/j.chemosphere.2014.09.046

Milić, N., Milanović, M., Letić, N. G., Sekulić, M. T., Radonić, J., Mihajlović, I., \& Miloradov, M. V. (2013). Occurrence of antibiotics as emerging contaminant substances in aquatic environment. International Journal of Environmental Health Research, 23, 296-310. https://doi.org/10. 1080/09603123.2012.733934

Nie, M., Yan, C., Xiong, X., Wen, X., Yang, X., Lv, Z., \& Dong, W. (2018). Degradation of chloramphenicol using a combination system of simulated solar light, $\mathrm{Fe}^{2+}$ and persulfate. Chemical Engineering Journal, 348, 455-463. https://doi.org/10.1016/j.cej.2018.04.124

Pan, X., Yan, L., Li, C., Qu, R., \& Wang, Z. (2017). Degradation of UV-filter benzophenone-3 in aqueous solution using persulfate catalyzed by cobalt ferrite. Chemical Engineering Journal, 326, 1197-1209. https://doi.org/10. 1016/j.cej.2017.06.068

Pan, X., Yan, L., Qu, R., \& Wang, Z. (2018). Degradation of the UV-filter benzophenone-3 in aqueous solution using persulfate activated by heat, metal ions and light. Chemosphere, 196, 95-104. https://doi.org/10.1016/j.chemo sphere.2017.12.152

Payan, A., Akbar Isari, A., \& Gholizade, N. (2019). Catalytic decomposition of sulfamethazine antibiotic and pharmaceutical wastewater using $\mathrm{Cu}-\mathrm{TiO}_{2} @$ functionalized SWCNT ternary porous nanocomposite: Influential factors, mechanism, and pathway studies. Chemical Engineering Journal, 361, 1121-1141. https://doi.org/10. 1016/j.cej.2018.12.118

Qi, Y., Qu, R., Liu, J., Chen, J., Al-Basher, G., Alsultan, N., Wang, Z., \& Huo, Z. (2019). Oxidation of flumequine in aqueous solution by UV-activated peroxymonosulfate: Kinetics, water matrix effects, degradation products and reaction pathways. Chemosphere, 237, 124484. https:// doi.org/10.1016/j.chemosphere.2019.124484

Qiu, H., Ling, C., Yuan, R., Liu, F., \& Li, A. (2019). Bridging effects behind the coadsorption of copper and sulfamethoxazole by a polyamine-modified resin. Chemical Engineering Journal, 362, 422-429. https://doi.org/10.1016/j. cej.2019.01.043

Sakulthaew, C., Chokejaroenrat, C., Satapanajaru, T., Chirasatienpon, T., \& Angkaew, A. (2020). Removal of $17 \beta$-estradiol using persulfate synergistically activated using heat and ultraviolet light. Water Air and Soil Pollution., 231, 247. https://doi.org/10.1007/ s11270-020-04571-5

Sharma, J., Mishra, I. M., Dionysiou, D. D., \& Kumar, V. (2015). Oxidative removal of Bisphenol A by UV-C/peroxymonosulfate (PMS): Kinetcs, influence of co-existing chemicals and degradation pathway. Chemical Engineering Journal, 276, 193-204. https://doi.org/10.1016/j.cej. 2015.04.021

Song, Y., Tian, J., Gao, S., Shao, P., Qi, J., \& Cui, F. (2017). Photodegradation of sulfonamides by $\mathrm{g}_{-} \mathrm{C}_{3} \mathrm{~N}_{4}$ under visible light irradiation: Effectiveness, mechanism and pathways. Applied Catalysis B: Environmental, 210, 88-96. https://doi.org/10.1016/j.apcatb.2017.03.059

Song, H., Yan, L., Jiang, J., Ma, J., Pang, S., Zhai, X., Zhang, W., \& Li, D. (2018). Enhanced degradation of antibiotic sulfamethoxazole by electrochemical activation of PDS using carbon anodes. Chemical Engineering Journal, 344, 12-20. https://doi.org/10.1016/j.cej.2018.03.050

Verlicchi, P., Al Aukidy, M., \& Zambello, E. (2012). Occurrence of pharmaceutical compounds in urban wastewater: Removal, mass load and environmental risk after a secondary treatment-A review. Science of the Total Environment, 429, 123-155. https://doi.org/10.1016/j.scitotenv. 2012.04.028

Wang, S., \& Wang, J. (2018). Radiation-induced degradation of sulfamethoxazole in the presence of various inorganic 
anions. Chemical Engineering Journal, 351, 688-696. https://doi.org/10.1016/j.cej.2018.06.137

Wang, Y., Zhang, H., Li, B., Yu, M., Zhao, R., Xu, X., \& Cai, L. (2019). $\gamma$-FeOOH graphene polyacrylamide carbonized aerogel as air-cathode in electro-Fenton process for enhanced degradation of sulfamethoxazole. Chemical Engineering Journal, 359, 914-923. https://doi.org/10. 1016/j.cej.2018.11.096

Wu, J., Wang, B., Blaney, L., Peng, G., Chen, P., Cui, Y., Deng, S., Wang, Y., Huang, J., \& Yu, G. (2019). Degradation of sulfamethazine by persulfate activated with organomontmorillonite supported nano-zero valent iron. Chemical Engineering Journal, 361, 99-108. https://doi.org/10. 1016/j.cej.2018.12.024

Xie, P., Ma, J., Liu, W., Zou, J., Yue, S., Li, X., Wiesner, M. R., \& Fang, J. (2015). Removal of 2-MIB and geosmin using UV/persulfate: Contributions of hydroxyl and sulfate radical. Water Research, 69, 223-233. https://doi.org/ 10.1016/j.watres.2014.11.029

Xu, Z., Wu, T., Cao, Y., Chen, C., Ke, S., Zeng, X., \& Lin, P. (2020). Efficient decomplexation of heavy metal-EDTA complexes by $\mathrm{Co}^{2+} /$ peroxymonosulfate process: The critical role of replacement mechanism. Chemical Engineering Journal, 392, 123639. https://doi.org/10.1016/j.cej. 2019.123639

Yang, H., Zhuang, S., Hu, Q., Hu, L., Yang, L., Au, C., \& Yi, B. (2018). Competitive reactions of hydroxyl and sulfate radicals with sulfonamides in $\mathrm{Fe}^{2+} / \mathrm{S}_{2} \mathrm{O}_{8}{ }^{2-}$ system: Reaction kinetics, degradation mechanism and acute toxicity. Chemical Engineering Journal, 339, 32-41. https://doi. org/10.1016/j.cej.2018.01.106

Yao, J., Gao, M., Guo, X., Ai, F., \& Wang, Z. (2019). Enhanced degradation performance of bisphenol $\mathrm{M}$ using peroxymonosulfate activated by zero-valent iron in aqueous solution: Kinetic study and product identification. Chemosphere, 221, 314-323. https://doi.org/10.1016/j.chemo sphere.2019.01.036

Yin, R., Guo, W., Wang, H., Du, J., Zhou, X., Wu, Q., Zheng, H., Chang, J., \& Ren, N. (2018). Selective degradation of sulfonamide antibiotics by peroxymonosulfate alone: Direct oxidation and nonradical mechanisms. Chemical
Engineering Journal, 334, 2539-2546. https://doi.org/10. 1016/j.cej.2017.11.174

Zeng, X., Qu, R., Feng, M., Chen, J., Wang, L., \& Wang, Z. (2016). Photodegradation of polyfluorinated dibenzo- $p$-dioxins in organic solvents: Experimental and theoretical studies. Environmental Science \& Technology, 50, 81288134. https://doi.org/10.1021/acs.est.6b02682

Zeng, X., Chen, J., Qu, R., Feng, M., \& Wang, Z. (2017). Degradation of octafluorodibenzo- $p$-dioxin by $\mathrm{UV} / \mathrm{Fe}(\mathrm{II}) /$ potassium monopersulfate system: Kinetics, influence of coexisting chemicals, degradation products and pathways. Chemical Engineering Journal, 319, 98-107. https://doi. org/10.1016/j.cej.2017.02.152

Zeng, X., Sun, X., Wang, H., \& Yu, Y. (2020). Computational study on $\mathrm{OH}$ addition reactions of three sulfonamides in aqueous solution. Chinese Journal of Structural Chemistry, 39, 48-56. https://doi.org/10.14102/j.cnki.0254-5861. 2011-2509

Zeng, X., Sun, X., \& Wang, Y. (2021). Photocatalytic degradation of flumequine by $\mathrm{N}$-doped $\mathrm{TiO}_{2}$ catalysts under simulated sunlight. Environmental Engineering Research, 26, 200524. https://doi.org/10.4491/eer.2020.524

Zhang, X., Yao, J., Zhao, Z., \& Liu, J. (2019). Degradation of haloacetonitriles with UV/peroxymonosulfate process: Degradation pathway and the role of hydroxyl radcals. Chemical Engineering Journal, 364, 1-10. https://doi.org/ 10.1016/j.cej.2019.01.029

Zhang, L., Guo, Y., Xie, R., Chen, L., Jiang, W., \& Jiang, X. (2020). An efficient catalytic composite material of mesoporous carbon loaded nano zero-valent iron as an activator for the degradation of sulfadiazine. Water Air and Soil Pollution., 231, 375. https://doi.org/10.1007/ s11270-020-04709-5

Publisher's Note Springer Nature remains neutral with regard to jurisdictional claims in published maps and institutional affiliations. 